\title{
A rare case of gastric mixed adenoneuroendocrine carcinoma (MANEC) with gastric Helicobacter pylori-negative mucosa-associated lymphoid tissue (MALT) lymphoma
}

\author{
Babikir Kheiri, Mohammed Osman, Douglas Congdon, Ghassan Bachuwa
}

Hurley Medical Center, Flint, Michigan, USA

\section{Correspondence to} Dr Ghassan Bachuwa gbachuw2@hurleymc.com

$\mathrm{BK}$ and $\mathrm{MO}$ contributed equally.

Accepted 17 June 2017
To cite: Kheiri B, Osman $\mathrm{M}$, Congdon D, et al. BMJ Case Rep Published Online First: [please include Day Month Year]. doi:10.1136/bcr-2017220421

\section{DESCRIPTION}

A 47-year-old African-American man presented to the emergency department with upper abdominal pain, nausea and vomiting. His symptoms were aggravated by eating. He reported $32 \mathrm{~kg}$ unintentional weight loss over 2 months' period. Abdominal examination revealed tenderness in the epigastric region. Abdominal CT scan showed mural wall thickening involving the gastric antrum and pylorus (figure 1). Subsequent oesophagogastroduodenoscopy (EGD) revealed a large mass occupying the gastric antrum (figure 2). Initial biopsy from the gastric mass showed poorly differentiated adenocarcinoma.

The patient underwent partial gastrectomy with gastrojejunostomy and the gastric specimen was examined. There was a transmurally invasive adenocarcinoma that has a remarkable variety of cell types and growth patterns, including tubular, mucinous, clear cell and a microglandular component (figure 3). The immunohistochemical stains were positive for monoclonal antibody-31 and cytokeratin-7, indicating adenocarcinomatous differentiation, and clearly positive for neuroendocrine markers chromogranin and synaptophysin (figure 4). Therefore, this area has neuroendocrine as well as adenocarcinomatous differentiation, qualifying this neoplasm as mixed adenoneuroendocrine carcinoma (MANEC). In addition to the carcinoma, there was a nodular atypical lymphoid infiltrate with follicles that have expanded marginal zones and disrupted/colonised germinal centres (figure 5). The atypical lymphoid cells were CD20

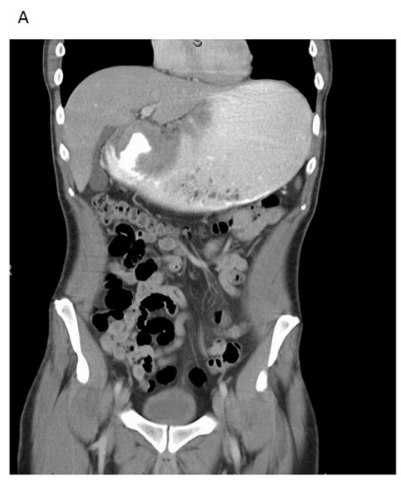

and BCL2-positive B cells that lack coexpression of CD5, CD10 and cyclin D1. The cells in the interfollicular areas were kappa light chain restricted and some had a vaguely plasmacytoid appearance, but they were negative for CD138, CD3 and CD5. These findings were diagnostic of mucosa-associated lymphoid tissue (MALT) lymphoma.

The final staging was T4a, N2, M0 (stage 111B) and the patient was started on adjuvant chemotherapy with fluorouracil, levoleucovorin and oxaliplatin for a total of 12 cycles. At the end of the treatment, the patient refused radiotherapy. Positron emission tomography scan at the time of the surgery did not show any evidence of distant metastasis. Follow-up CT abdomen and EGD at 24 months showed no evidence of recurrence. Our patient did not show any extragastric hormonal symptoms such as diarrhoea, facial flushing or wheezing.

Gastric MANEC is a rare form of mixed exocrine-endocrine tumour with each component representing at least $30 \%$ to fulfil the diagnosis. ${ }^{1}$ These tumours were recently recognised in 2010 by the WHO classification of tumours as a separate entity. ${ }^{1}$ Recognition of MANEC is an important step since these tumours overall carry a poor prognosis and early treatment plays a vital role to improve survival. ${ }^{1}$

Helicobacter pylori-negative gastric MALT lymphoma comprises only $10 \%$ of gastric MALT lymphoma with the remaining developing secondary to $H$. pylori infection. ${ }^{2}$ The proposed aetiological factors in this form of tumour are infection with

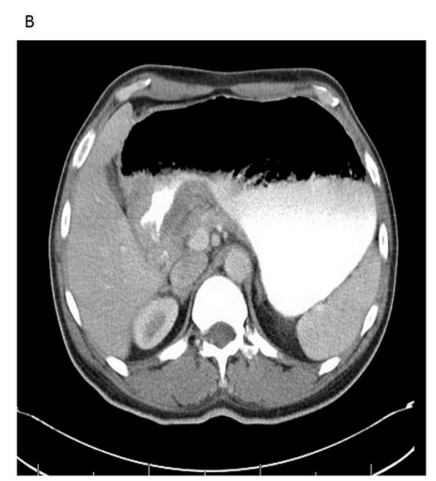

Figure 1 (A) Coronal section of the CT abdomen with intravenous and oral contrast showing wall thickening at the level of the gastric antrum. (B) Axial section of the CT abdomen with intravenous and oral contrast showing wall thickening at the level of the gastric antrum and pylorus. 

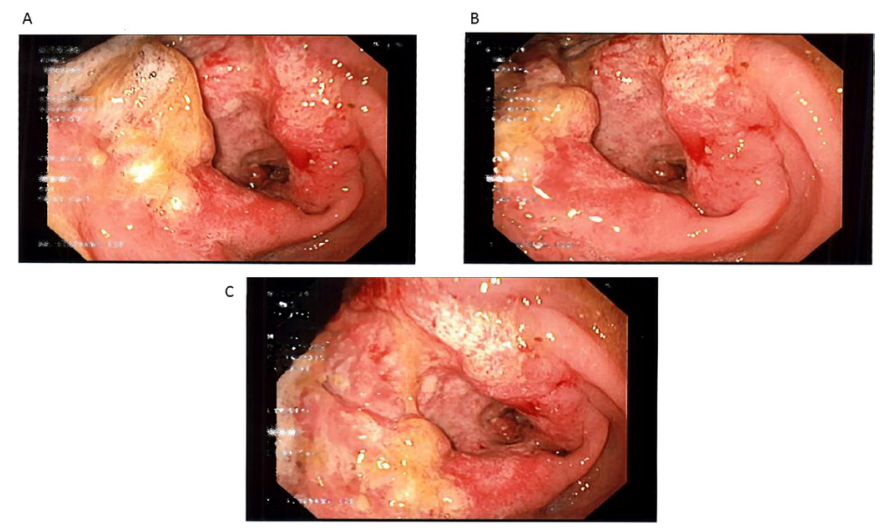

Figure 2 Upper gastrointestinal endoscopy showing a mass in the gastric antrum (A. B. C: different views).
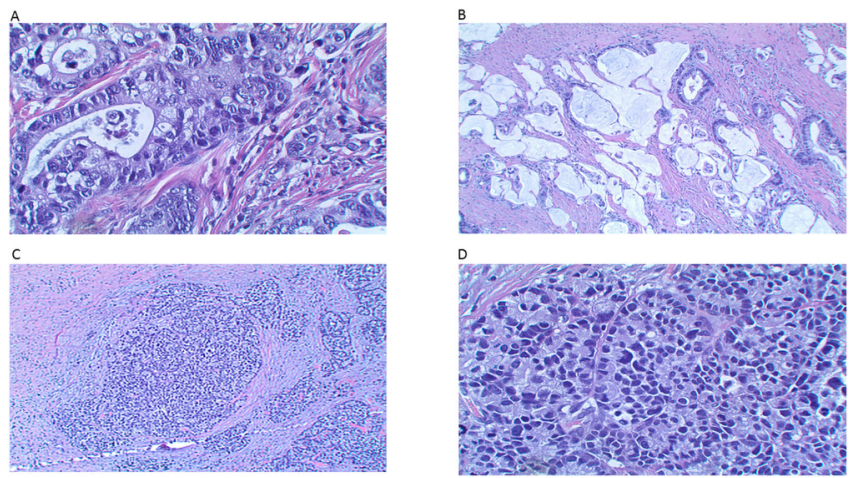

Figure 3 Sections of invasive adenocarcinoma showing a variety of cell types and growth patterns, including $(A)$ poorly differentiated adenocarcinoma (H\&E, X400); (B) adenocarcinoma showing mucinous differentiation (H\&E, X100); (C) microglandular pattern (H\&E, X100); (D) microglandular pattern (H\&E, X400).
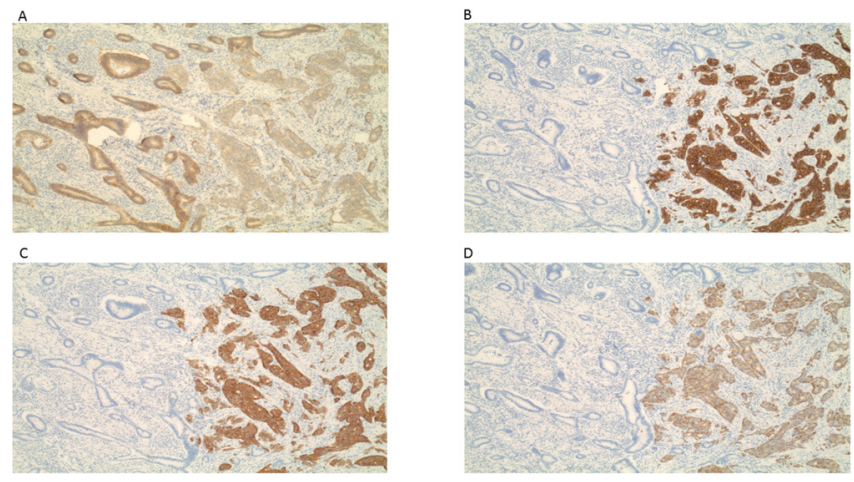

Figure 4 An area of the neoplasm showing neuroendocrine as well as adenocarcinomatous differentiation by immunohistochemical staining, including (A) monoclonal antibody-31 stains both pure adenocarcinomatous area and an area of microglandular differentiation (immunoperoxidase, X40). (B-D) The microglandular area only shows expression of cytokeratin-7, synaptophysin and chromogranin, respectively (immunoperoxidase, X40).

different form of pathogen other than $H$. pylori, connective tissue disease or genetic mutation. ${ }^{2}$

Several cases were reported in the literature of synchronous gastric adenocarcinoma and MALT lymphoma with variable detection rate of H. pylori. ${ }^{3}$ To our best knowledge, this is the

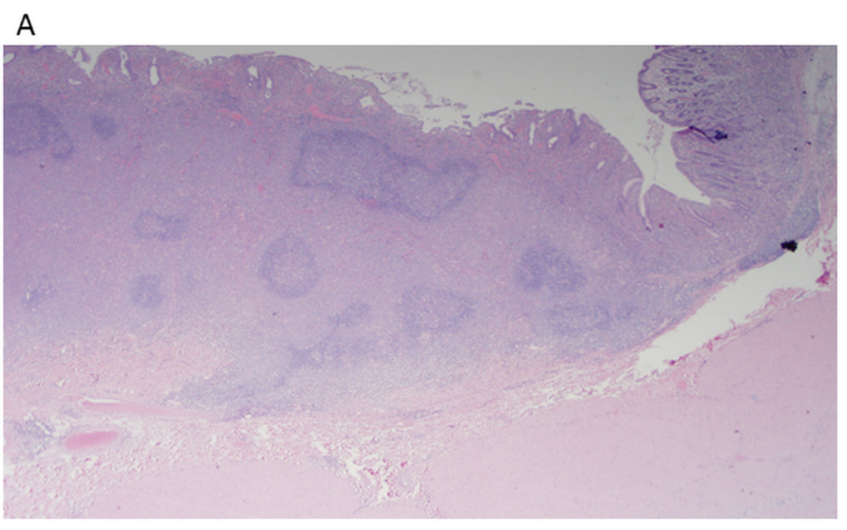

B

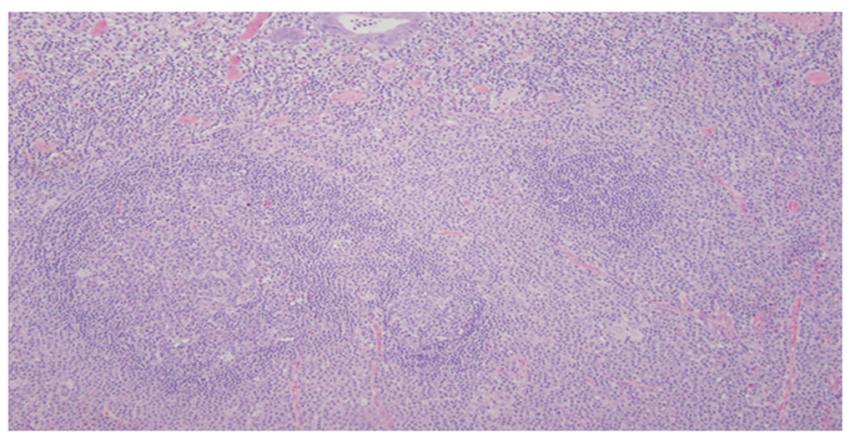

Figure 5 Sections of the mucosa-associated lymphoid tissue lymphoma showing (A) stomach with a nodular atypical lymphoid infiltrate showing follicles with expanded marginal zones and surrounding scar (H\&E, X20); (B) expanded marginal zones with disrupted/colonised germinal centres (H\&E, X100).

\section{Learning points}

- Gastric mixed adenoneuroendocrine carcinoma (MANEC) is a rare and aggressive type of cancer and was included in the updated WHO calcification of digestive system in 2010. Many cases, therefore, went unreported prior to this update.

- Helicobacter pylori-negative gastric mucosa-associated lymphoid tissue lymphoma can potentially be associated with MANEC tumour.

- The aggressive behaviour of gastric MANEC is largely secondary to characteristics of the neuroendocrine component and early detection and treatment can play a vital role to improve survival.

only reported case up to date of gastric MANEC with $H$. pylo$r$-negative gastric MALT lymphoma.

Acknowledgements The authors acknowledge Dr. Samer Al Hadidi, Assistant Professor of Medicine, Michigan State University/ Hurley Medical Center for his supervisory role in patient managment. The authors would like to thank Dr. Scott R. Owens, Associate Professor of Pathology, University of Michigan for his help in the pathological diagnosis.

Contributors BK and MO planned, designed, wrote and critically revised the manuscript. They had an important role to facilitate the work between different authors. They also did the literature review. They also participated in images preparation. DC and GB wrote and critically revised the manuscript. DC also did the literature review. He also participated in images preparation and figures caption and pathological description. GB also participated in images preparation and selection. He played a vital role in writing the learning points.

Competing interests None declared.

Patient consent Obtained. 
Provenance and peer review Not commissioned; externally peer reviewed.

(c) BMJ Publishing Group Ltd (unless otherwise stated in the text of the article) 2017. All rights reserved. No commercial use is permitted unless otherwise expressly granted.

\section{REFERENCES}

1 Nie L, Li M, He X, et al. Gastric mixed adenoneuroendocrine carcinoma: correlation of histologic characteristics with prognosis. Ann Diagn Pathol 2016;25:48-53.
2 Asano N, lijima K, Koike T, et al. Helicobacter pylori-negative gastric mucosa-associated lymphoid tissue lymphomas: A review. World I Gastroenterol 2015;21:8014-20.

3 Chan AO, Chu KM, Yuen ST, et al. Synchronous gastric adenocarcinoma and mucosa-associated lymphoid tissue lymphoma in association with Helicobacter pylori infection: comparing reported cases between the East and West. Am J Gastroenterol 2001:96:1922-4.

Copyright 2017 BMJ Publishing Group. All rights reserved. For permission to reuse any of this content visit http://group.bmj.com/group/rights-licensing/permissions.

BMJ Case Report Fellows may re-use this article for personal use and teaching without any further permission.

Become a Fellow of BMJ Case Reports today and you can:

- Submit as many cases as you like

Enjoy fast sympathetic peer review and rapid publication of accepted articles

- Access all the published articles

Re-use any of the published material for personal use and teaching without further permission

For information on Institutional Fellowships contact consortiasales@bmjgroup.com

Visit casereports.bmj.com for more articles like this and to become a Fellow 